\title{
Estimation of Genetic Parameters for Direct and Maternal Effects on Litter Size and Teat Numbers in Korean Seedstock Swine Population
}

\author{
Guy-Bong Song ${ }^{1}$, Jun-Ho Lee ${ }^{2}$ and Deuk-Hwan Lee ${ }^{2} *$ \\ ${ }^{1}$ Korean Animal Improvement Association, ${ }^{2}$ Department of Animal Life and Environmental Science, College of Agriculture
} \& Life Science, Hankyong National University

\begin{abstract}
The objective of this study was to estimate genetic parameters for total number of born (TNB), number of born alive (NBA) and teat numbers (TN) of Landrace and Yorkshire breeds in Korean swine population using multiple trait animal model procedures. Total numbers of 4,653 records for teat numbers and 8,907 records for TNB and NBA collected from 2004 to 2008 on imported breeding pigs and their litter size records were used in this study. To find the appropriate model for estimation of genetic parameters (heritabilities and genetic correlations), five statistical models (two models for reproductive traits, two models for teat numbers, one model for combining these traits) considering only direct additive genetic effects, including maternal effects were used and Akaike information criteria (AIC) of each two models for reproductive traits and teat trait were compared. The means and standard deviations of TNB, NBA, and TN were 11.52 $\pm 3.34,10.55 \pm 2.96$ and 14.30 \pm 0.83 , respectively. Estimated heritabilities for TNB and NBA traits using the model which considered only additive genetic effect were low $(0.06$ and 0.05 , respectively). However, estimated heritabilities considering maternal genetic effects were a little bit higher than that of the model considering only additive genetic effect ( 0.09 for TNB and NBA, respectively). Estimated heritability for TN using the model which considered only additive genetic effect was 0.40 . However, estimated heritability of direct genetic effects from a model considering maternal genetic effect was high (0.60). All results of AIC statistics, the models considering maternal effect was more appropriate than the models considering only additive genetic effect. Genetic correlations of direct additive genetic effect between litter size (TNB, NBA) and teat numbers were low ( -0.18 and -0.14 , respectively). However, genetic correlations of maternal effect between litter size (TNB, NBA) and teat numbers were a little bit higher than those of direct additive genetic effect $(0.08$ and 0.16 , respectively).
\end{abstract}

(Key words : Pig, Teat numbers, Genetic parameters, Maternal effects)

\section{INTRODUCTION}

The reproduction traits like litter size are major economic traits especially for the seedstock swine producers. However, it is not easy to improve these reproduction traits because of its low heritability (Su et al., 2007, Barot et al., 2003). Therefore, it is important to estimate breeding value with more accurate genetic parameters. Genetic improvement of teat numbers has not been performed in Korea because of the results of study that there are almost zero correlations between teat numbers and production traits (Frank et al., 1961) and normally little possibilities of more litter size than teat numbers (Skjervold, 1963). However, it is considerable factor from viewpoint that it could be a measurement of lactating ability of sow and one of the important judging factor for imported sow in Korea. These traits are female related traits and seemed to have maternal effect and correlations. Consideration of maternal effects in the evaluation model of litter size was recommended by the result of simulation study of Roehe and Kennedy (1993) and there is no study about estimation of maternal effect for teat numbers in swine. The objective of this study was to estimate genetic parameters comparing different models and considering maternal effect for total number of born (TNB), number of born alive (NBA) and teat numbers (TN) of Landrace and Yorkshire breeds in Korean swine using multiple trait animal model procedures.

\section{MATERIALS AND METHODS}

\section{Data description}

In Korea, Landrace and Yorkshire breeds are widely used as the maternal lines because of good reproductive ability

* Corresponding author: Deuk-hwan Lee, Department of Animal Life Resources, Hankyong National Univ. Seokjeong-dong Anseong-si Gyeonggi-do, Rep. of Korea 456-749. Tel: 031-670-5091, Fax: 031-676-5091, E-mail: dhlee@hknu.ac.kr 
and are imported from other countries every year. When pure breed line pigs are imported, teat numbers are recorded as it is one of the exterior judging parameters. A total of 4,653 records for teat numbers and 8,907 records for TNB and NBA collected from 2004 to 2008 on imported breeding were used in this study (Table 1).

Table 1. Number of records for litter size and teat numbers by breeds used in this study from Korean Swine breeding stock population

\begin{tabular}{ccc}
\hline Trait & Landrace & Yorkshire \\
\hline \hline Litter size & 2,996 & 5,911 \\
\hline Teat numbers & 1,651 & 3,002 \\
\hline
\end{tabular}

\section{Statistical analysis}

To estimate genetic parameters (heritabilities and genetic correlations), five statistical models were used in this study. For TNB and NBA, genetic parameters were estimated by Model 1 considering animal effect and permanent environmental effect and Model 2 additionally considering maternal effect in Model 1. For TN, Model 3 and Model 4 were used with the same source of Model 1 and Model 2 except for permanent environmental effect because of no repeated records. Model 5 was used for estimation of genetic correlations among TNB, NBA and TN and comparison of genetic parameter change (Table 2). To find the appropriate model for estimation of genetic parameters Akaike information criteria (AIC) of each two models for reproductive traits and teat trait were compared. Variance components were estimated using REML algorithm (Patterson and Thompson, 1971) and REML software package (REMLF90; Misztal, 2001) was used. Models by traits and considered effects were as below:

(1) Generalized mixed model equation for total number of born (TNB), number of born alive (NBA)

Model 1: $\mathrm{y}=\mathrm{Xb}+\mathrm{Z}_{1} \mathrm{~d}+\mathrm{Z}_{2} \mathrm{pe}+\mathrm{e}$
Model 2: $\mathrm{y}=\mathrm{Xb}+\mathrm{Z}_{1} \mathrm{~d}+\mathrm{Z}_{2} \mathrm{~m}+\mathrm{Z}_{3} \mathrm{pe}+\mathrm{e}$

Equation in model 2 can be shown as matrix notation as below:

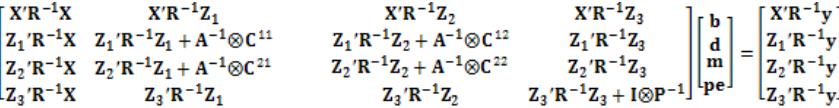

$$
\begin{aligned}
& \mathbf{C}=\mathbf{G}^{-1}=\left[\begin{array}{cc}
\mathbf{G}_{\mathrm{d}}^{2} & \mathbf{G}_{\mathrm{dm}} \\
\mathbf{G}_{\mathrm{dm}} & \mathbf{G}_{\mathrm{m}}^{2}
\end{array}\right]^{-1}=\left[\begin{array}{ll}
\mathrm{C}^{11} & \mathbf{C}^{12} \\
\mathrm{C}^{21} & \mathrm{C}^{22}
\end{array}\right]
\end{aligned}
$$

where $y=$ observation vector of TNB and NBA, $\mathrm{X}=$ incidence matrix relating to fixed effect, $\mathrm{b}=$ fixed effect vector (breed, herd, parity), $\mathrm{Z}=$ incidence matrix relating to random effect, d: direct additive genetic effect, m: maternal effect, pe: permanent environmental effect, R: residual variancecovariance matrix of traits, e: residual effect, G: additive genetic variance-covariance matrix of traits, $C^{1 j}$ : partitioned matrix of $G$ inverse matrix, $P$ : variance-covariance matrix $(2 \times 2)$ of permanent environmental effect, A: additive genetic relationship matrix. $\otimes$ : Kronecker product

(2) Generalized mixed model equation for teat number (TN)

Model 3: $\mathrm{y}=\mathrm{Xb}+\mathrm{Z}_{1} \mathrm{~d}+\mathrm{e}$

Model 4: $\mathrm{y}=\mathrm{Xb}+\mathrm{Z}_{1} \mathrm{~d}+\mathrm{Z}_{2} \mathrm{~m}+\mathrm{e}$

Equation in model 4 can be shown as matrix notation as below:

$$
\begin{aligned}
& {\left[\begin{array}{ccc}
X^{\prime} R^{-1} X & X^{\prime} R^{-1} Z_{1} & X^{\prime} R^{-1} Z_{2} \\
Z_{1} R^{-1} X & Z_{1} R^{-1} Z_{1}+A^{-1} g^{11} & Z_{1} R^{-1} Z_{2}+A^{-1} g^{12} \\
Z_{2} R^{-1} X & Z_{2} R^{-1} Z_{1}+A^{-1} g^{21} & Z_{2} R^{-1} Z_{2}+A^{-1} g^{22}
\end{array}\right]\left[\begin{array}{l}
b \\
d \\
m
\end{array}\right]=\left[\begin{array}{l}
X^{\prime} R^{-1} y \\
Z_{1} R^{-1} y \\
Z_{2} R^{-1} y
\end{array}\right]} \\
& \mathbf{G}^{-1}=\left[\begin{array}{cc}
\sigma_{d}^{2} & \sigma_{d m} \\
\sigma_{d m} & \sigma_{m}^{2}
\end{array}\right]^{-1}=\left[\begin{array}{ll}
g^{11} & g^{12} \\
g^{21} & g^{22}
\end{array}\right]
\end{aligned}
$$

where $\mathrm{g}^{\mathrm{ij}}$ : elements of $\mathrm{G}$ inverse matrix

(3) Generalized mixed model equation for TNB, NBA and TN

\begin{tabular}{|c|c|c|c|c|c|c|c|c|}
\hline \multirow{2}{*}{$\begin{array}{c}\text { Trait } \\
\text { Random effect }\end{array}$} & \multicolumn{3}{|c|}{ TNB } & \multicolumn{3}{|c|}{ NBA } & \multicolumn{2}{|c|}{$\mathrm{TN}$} \\
\hline & $\mathrm{D}$ & $\mathrm{M}$ & $\mathrm{PE}$ & $\mathrm{D}$ & $\mathrm{M}$ & $\mathrm{PE}$ & $\mathrm{D}$ & $\mathrm{M}$ \\
\hline Model 1 & 0 & - & 0 & 0 & - & 0 & - & - \\
\hline Model 2 & 0 & 0 & 0 & 0 & 0 & 0 & - & - \\
\hline Model 3 & - & - & - & - & - & - & 0 & - \\
\hline Model 4 & - & - & - & - & - & - & 0 & 0 \\
\hline Model 5 & O & 0 & 0 & 0 & 0 & 0 & 0 & 0 \\
\hline
\end{tabular}

Table 2. Random effects in various mixed model equations by traits in this study from Korean Swine breeding stock population

D: direct additive genetic effect, M: maternal effect, PE: permanent environment effect, TNB: total number of born, NBA: number of born alive, TN: teat number 
Model 5: $\mathrm{y}=\mathrm{Xb}+\mathrm{Z}_{1} \mathrm{~d}+\mathrm{Z}_{2} \mathrm{~m}+\mathrm{Z}_{3} \mathrm{pe}+\mathrm{e}$

Equation in model 5 can be shown as matrix notation as below:

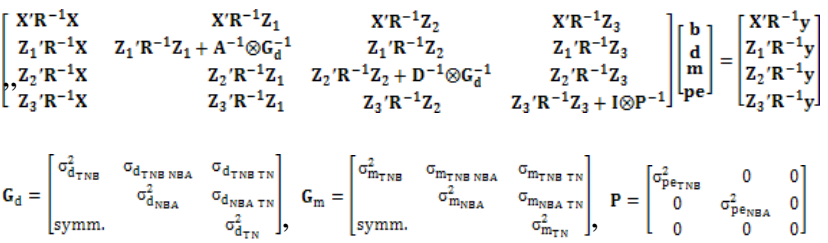

where $G_{d}, G_{m}$ : variance covariance matrix of direct additive genetic effect and maternal effect, respectively, D: additive genetic relationship matrix of dam.

\section{RESULTS AND DISCUSSION}

The means and standard deviations of TNB, NBA and TN were $11.52 \pm 3.34,10.55 \pm 2.96$ and $14.30 \pm 0.83$, respectively. Means and standard deviations for the traits by breed are summarized in Table 3 and mean and standard deviation of litter size by TN are summarized in Table 4.

Estimated heritability, genetic correlation of the direct additive genetic effect and maternal effect and AIC for TNB and NBA using the model 1 and model 2 are summarized in Table 5.

Estimated heritabilities of Model 1 considering only additive genetic effect were low (0.06 and 0.05 for TNB and NBA, respectively). However, estimated heritability of direct additive genetic effect considering maternal genetic effect was a little bit higher than that of the model considering only additive genetic effect $(0.09$ for TNB and NBA, respectively). Chen et al. (2002) reported a similar heritability of NBA considering only direct additive genetic effect and additionally considering maternal effect in Landrace (0.08, 0.07 , respectively) and in Yorkshire (0.10, 0.10, respectively). Estimated genetic correlations between TBN and NBA were 0.89 in model 1 and 0.91 in model 2. Estimated heritabilities of maternal effects were 0.03 for TNB and 0.04 for NBA.

Table 3. Means and standard deviations for total number of born (TNB), number of born alive (NBA) and teat number (TN) by breed in this study from Korean Swine breeding stock population

\begin{tabular}{ccc}
\hline Trait & Landrace & Yorkshire \\
\hline \hline TNB & $11.11 \pm 3.17$ & $11.71 \pm 3.40$ \\
NBA & $10.22 \pm 2.84$ & $10.70 \pm 3.00$ \\
TN & $14.34 \pm 0.85$ & $14.27 \pm 0.84$ \\
\hline
\end{tabular}

Table 4. Means and standard deviation for total number of born (TNB) and number of born alive (NBA) by teat number (TN) on each breed in this study from Korean Swine breeding stock population

\begin{tabular}{cccrr}
\hline Breed & TN & $\begin{array}{c}\text { Number } \\
\text { of records }\end{array}$ & $\begin{array}{c}\text { TNB } \\
\text { Mean } \pm \text { SD }\end{array}$ & \multicolumn{1}{c}{$\begin{array}{c}\text { NBA } \\
\text { Mean } \pm \text { SD }\end{array}$} \\
\hline \hline & 12 & 57 & $10.88 \pm 2.89$ & $10.02 \pm 2.75$ \\
& 13 & 62 & $11.26 \pm 3.50$ & $10.10 \pm 3.18$ \\
Landrace & 14 & 2,108 & $11.05 \pm 3.16$ & $10.23 \pm 2.82$ \\
& 15 & 264 & $11.31 \pm 2.95$ & $10.20 \pm 2.64$ \\
& 16 & 470 & $11.34 \pm 3.21$ & $10.28 \pm 2.91$ \\
& 17 & 23 & $9.41 \pm 3.38$ & $9.00 \pm 3.05$ \\
& 18 & 12 & $10.92 \pm 3.95$ & $9.92 \pm 3.57$ \\
\hline & 11 & 6 & $11.40 \pm 2.42$ & $10.60 \pm 1.96$ \\
& 12 & 98 & $11.65 \pm 2.99$ & $10.67 \pm 2.57$ \\
Yorkshire & 13 & 182 & $11.26 \pm 2.94$ & $10.46 \pm 2.68$ \\
& 14 & 4,363 & $11.62 \pm 3.36$ & $10.64 \pm 1.99$ \\
& 15 & 837 & $11.01 \pm 3.41$ & $9.97 \pm 2.93$ \\
& 16 & 11 & $12.41 \pm 3.56$ & $11.18 \pm 3.09$ \\
& 16 & 11 & $15.00 \pm 1.71$ & $13.73 \pm 1.29$ \\
\hline
\end{tabular}

Genetic correlations between maternal effects for TNB and NBA were 0.78. Results of AIC test, the models considering maternal effects were more appropriate than the models considering only additive genetic effect.

Estimated heritability for TN using the model which considered only additive genetic effect was 0.40. However,

Table 5. Estimates of heritabilities and genetic correlations for total number of born (TNB) and number of born alive (NBA) on Model 1 and Model 2 in this study from Korean Swine breeding stock population

\begin{tabular}{lcc}
\hline & Model 1 & Model 2 \\
\hline \hline $\mathrm{h}_{\mathrm{dTNB}}^{2}$ & 0.06 & 0.09 \\
$\mathrm{~h}_{\mathrm{dNBA}}^{2}$ & 0.05 & 0.09 \\
$\mathrm{~h}_{\mathrm{mTNB}}^{2}$ & - & 0.04 \\
$\mathrm{~h}_{\mathrm{mNBA}}^{2}$ & - & 0.03 \\
$\mathrm{pe}_{(\mathrm{TNB})}$ & 0.12 & 0.12 \\
$\mathrm{pe}_{(\mathrm{NBA})}$ & 0.12 & 0.12 \\
$\mathrm{rg}_{\mathrm{g}}\left(\mathrm{d}_{\mathrm{TNB}}, \mathrm{d}_{\mathrm{NBA}}\right)$ & 0.89 & 0.91 \\
$\mathrm{rg}_{\mathrm{g}}\left(\mathrm{m}_{\mathrm{TNB}}, \mathrm{m}_{\mathrm{NBA}}\right)$ & - & 0.78 \\
$\mathrm{rg}_{\mathrm{g}}\left(\mathrm{d}_{\mathrm{TNB}}, \mathrm{m}_{\mathrm{TNB}}\right)$ & - & -0.85 \\
$\mathrm{rg}_{\mathrm{g}}\left(\mathrm{d}_{\mathrm{NAB}}, \mathrm{m}_{\mathrm{NAB}}\right)$ & - & -0.92 \\
$\mathrm{r}_{\mathrm{g}}\left(\mathrm{d}_{\mathrm{TNB}}, \mathrm{m}_{\mathrm{NBA}}\right)$ & - & -0.87 \\
$\mathrm{r}_{\mathrm{g}}\left(\mathrm{m}_{\mathrm{TNB}}, \mathrm{d}_{\mathrm{NBA}}\right)$ & - & -0.65 \\
$\mathrm{AIC}$ & 41743 & 32737 \\
\hline
\end{tabular}


estimated heritability of direct genetic effects from a model considering maternal genetic effect was much higher (0.60) than heritability considering only additive genetic effect. This results were higher than that reported by Fernandez et al. (0.36; 2004), Pumfrey et al. (0.32, 0.44; 1980), Mckay and Rahnefeld (0.23 0.45; 1990), Bejar et al. (0.19 0.31; 1993). Estimated heritability of maternal effect for TN was 0.25 and AIC results was better in model 4 considering maternal effect (Table 6.).

Estimated heritabilities for TBN, NBA and TN using model 5 were $0.05,0.05$ and 0.32 , respectively. Genetic correlations of additive genetic effect between litter size (TNB, NBA) and teat numbers were low $(-0.18$ and -0.14 , respectively). However, genetic correlations of maternal effect between litter size (TNB, NBA) and teat numbers were bit higher than those of direct additive genetic effect ( 0.08 and 0.16 , respectively) (Table 7).

Table 6. Estimates of heritabilities and genetic correlations for teat number (TN) in Model 3 and Model 4 in this study from Korean Swine breeding stock population

\begin{tabular}{lcc}
\hline & Model 3 & Model 4 \\
\hline \hline $\mathrm{h}_{\mathrm{dTN}}^{2}$ & 0.40 & 0.60 \\
$\mathrm{~h}^{2}{ }_{\mathrm{mTN}}$ & - & 0.25 \\
$\mathrm{r}_{\mathrm{g}}\left(\mathrm{d}_{\mathrm{TN}}, \mathrm{m}_{\mathrm{TN}}\right)$ & - & -0.68 \\
$\mathrm{AIC}$ & 10514 & -4908 \\
\hline
\end{tabular}

Table 7. Estimates of heritabilities and genetic correlations for total number of born (TNB), number of born alive (NBA) and teat number (TN) in Model 5 in this study from Korean Swine breeding stock population

\begin{tabular}{lc}
\hline & Model 5 \\
\hline \hline $\mathrm{h}_{\mathrm{dTNB}}^{2}$ & 0.05 \\
$\mathrm{~h}_{\mathrm{dNBA}}^{2}$ & 0.05 \\
$\mathrm{~h}_{\mathrm{dTN}}^{2}$ & 0.32 \\
$\mathrm{~h}_{\mathrm{mTBN}}^{2}$ & 0.01 \\
$\mathrm{~h}_{\mathrm{mNBA}}^{2}$ & 0.00 \\
$\mathrm{~h}_{\mathrm{mTN}}^{2}$ & 0.10 \\
$\mathrm{pe}_{(\mathrm{TNB})}$ & 0.06 \\
$\mathrm{pe}_{(\mathrm{NBA})}$ & 0.06 \\
$\mathrm{r}_{\mathrm{g}}\left(\mathrm{d}_{\mathrm{TNB}}, \mathrm{d}_{\mathrm{NBA}}\right)$ & 0.89 \\
$\mathrm{r}_{\mathrm{g}}\left(\mathrm{d}_{\mathrm{TNB}}, \mathrm{d}_{\mathrm{TN}}\right)$ & 0.18 \\
$\mathrm{r}_{\mathrm{g}}\left(\mathrm{d}_{\mathrm{NBA}}, \mathrm{d}_{\mathrm{TN}}\right)$ & 0.14 \\
$\mathrm{r}_{\mathrm{g}}\left(\mathrm{m}_{\mathrm{TNB}}, \mathrm{m}_{\mathrm{NBA}}\right)$ & 0.92 \\
$\mathrm{r}_{\mathrm{g}}\left(\mathrm{m}_{\mathrm{TNB}}, \mathrm{m}_{\mathrm{TN}}\right)$ & 0.08 \\
$\mathrm{r}_{\mathrm{g}}\left(\mathrm{m}_{\mathrm{NBA}}, \mathrm{m}_{\mathrm{TN}}\right)$ & 0.16 \\
\hline
\end{tabular}

\section{REFERENCES}

Barot, D., Noguera, J. L., Alfonso, L. and Estany, J. 2003. Fixed or random contemporary effects in Hampshire and Landrace swine: I. Maternal traits. J. Anim. Sci. 70:89.

Bejar, F., Rodriguez, M. C. and Toro, M. A. 1993. Estimation of genetic trends for weaning weight and teat number in Iberian pigs using mixed model methodology. Live. Prod. Sci. 33:239.

Chen, P., Baas, T. J., Mabry, J. W., Dekkers, J. C. M. and Koehler, K. J. 2002. Genetic parameters and trends for litter traits in U.S. Yorkshire, Duroc, Hampshire, and Landrace pigs. J. Anim. Sci. 81:46-53.

Fernandez, A., Toro, M., Rodriguez, C. and Silio, L 2004. Heterosis and epistasis for teat number and fluctuating asymmetry in crosses between Jiaxing and Iberian pigs. Heredity (2004) 93, 222-227.

Frank, D. Enfield and Rempel, W. E. 1961. Inheritance of Teat Number and Relationship of Teat Number to Various Maternal Traits in Swine J. Anim. Sci. 20:876-879.

Mckay, R. M. and Rahnefeld, G. W. 1990. Heritability of teat number in swine. Can. J. Anim. Sci. 70:425.

Misztal, I. 2001. BLUPF90 family of programs. http://nce.ads.uga. edu/ ignacy/newprograms.html

Patterson, H. D. and R. Thompson. 1971. Recovery of interblock information when block sizes are unequal, Biometrika 58:545554.

Pumfrey, R. A., Johnson, P. K., Cunningham, P. J. and Zimmerman, D. R. 1980. Inheritance of teat number and it's relationship to maternal tratis in swine. J. Anim. Sci. 50:1057.

Roehe, R. and Kennedy, B. W. 1993. The Influence of Maternal Effects on Accuracy of Evaluation of Litter Size in Swine. J. Anim. Sci. 71:2353-2364.

Roehe, R. and Kennedy, B. W. 1993. Effect of selection for maternal and direct genetic effects on genetic improvement of litter size in swine J. Anim. Sci. 71:2891-2904.

Skjervold, H. 1963. Inheritance of teat number in swine and the relationship to performance. Acta Agric. Scand. 13:323.

Su, G., Lund, M. S. and Sorensen, D. 2007. Selection for litter size at day five to improve litter size at weaning and piglet survival rate. J. Anim. Sci. 82:1385-1392.

(Received April 26, 2010; Revised June 3, 2010; Accepted June 8, 2010) 